Precordial mapping of the left hemithorax provides a measure of area, time course, and severity of ischaemic ECG changes. In addition it permits the identification of the precordial position showing the earliest and maximum ECG signs of ischaemia. In 35 of the patients this area was separate from the conventional V5 position. ${ }^{4}$ The implications of this finding became clear when 24-hour recordings of the ECG in these patients were taken from V5 and the precordial area of maximum change. More episodes of ischaemia were recorded from the centre of the projected area of abnormal ECG signs in each patient than from V5.

The technical requirements for ambulatory monitoring of ST-segment changes have been examined by other workers. ${ }^{6}$ Baseline stability, adequate low-frequency response, the effects of posture, and respiration are all important. ${ }^{7}$ Although the lowfrequency response of our recorder was adequate to $0 \cdot 15 \mathrm{~Hz}$, the tests used could not detect important differences when comparing its results with those of an ink-jet recorder responding to $0.05 \mathrm{~Hz}$ ( $<3 \mathrm{~dB}$ down). In particular, false-positive planar ST-segment depression could not be detected under any circumstances.

Several studies have shown that planar depression of the ST segment of $1 \mathrm{~mm}$ or more lasting for $0.08 \mathrm{~s}$ or longer is a consistent and discriminate sign of myocardial ischaemia. ${ }^{2}$ This study found many more episodes of ischaemia than might have been suspected from the reported chest pain, and only $16 \%$ of ischaemic episodes were accompanied by reported pain. If this percentage is variable then the frequency of angina may not accurately represent the severity of the condition.

The 24-hour recordings provide a measure of frequency, severity, and timing of ischaemic episodes and of their relation to chest pain, activities, heart rate, and drug administration. Ischaemic episodes were recorded at night during sleep and particularly between 4 am and 6 am. It might be interesting and of therapeutic importance to relate this finding to blood concentrations of antianginal drugs, the arterial oxygen content, heart rate, blood pressure, circulating catecholamines, and the presence or absence of rapid-eye-movement sleep.

Thus this study showed that precordial ECG mapping during $\stackrel{\mathbb{D}}{2}$ exercise and 24-hour ambulatory recording of ST-segment $\stackrel{.}{\Rightarrow}$ changes provide objective measurements that may be of value $\overrightarrow{\vec{D}}$ in assessing angina and myocardial ischaemia. More information $\overline{0}$ is obtained when the individual precordial area of maximum $\frac{\overline{0}}{0}$ ECG changes in each patient is used for 24-hour recording of $\overline{\frac{m}{2}}$ ischaemic episodes. Under one-fifth of the ECG episodes of $\bar{\nabla}$ myocardial ischaemia were accompanied by pain, and ischaemic episodes occurred during sleep, particularly between 4 am and $6 \mathrm{am}$.

This work was supported in part by the Wellcome Trust and the British Heart Foundation. We gratefully acknowledge the help given by Dr Dennis Krikler and Professor J Goodwin.

\section{References} Rosing, D R, Reichek, N, and Perloff, J K, American Heart fournal, $\vec{G}$
1974, 87, 584.

${ }^{2}$ Mason, R E, et al, Circulation, $196^{\prime} i, 36,517$.

3 Fox, K M, Selwyn, A P, and Shillingford, J P, British Heart Fournal. In press.

4 Wolf, E, Tzivoni, D, and Stern, S, British Heart fournal, 1974, 36, 90. 5 Goldstein, R, and Epstein, S, Progress in Cardiovascular Disease, 1972, 14, 360.

6 Berson, A S, and Pipberger, H V, American Heart fournal, 1966, 7, 779.

7 Stern, S, and Tzivoni, D, American fournal of Cardiology, 1973, 32, 17.

\title{
Precordial exercise mapping: improved diagnosis of coronary artery disease
}

\author{
KIM FOX, ANDREW SELWYN, JOHN SHILLINGFORD
}

British Medical fournal, 1978, 2, 1596-1598

\section{Summary and conclusions}

Surface mapping of the exercise electrocardiogram (ECG) provides a measure of the precordial area, severity, and time course of ST-segment changes occurring after exercise. Sixteen-lead isopotential surface maps were recorded before and after exercise in 109 patients with probable angina who subsequently underwent coronary arteriography. In addition, exercise ECGs with three orthogonal leads were obtained in 53 of these patients, and with a single unipolar chest lead in all 109. Of the 109 patients, 85 had significant $(\geqslant 70 \%)$ narrowing of at least one major coronary artery. The sensitivities of the precordial surface mapping, orthogonal leads, and

\footnotetext{
Division of Cardiovascular Disease, Royal Postgraduate Medical School, Hammersmith Hospital, London W12 OHS

KIM FOX, MRCP, research fellow

ANDREW SELWYN, MRCP, lecturer

JOHN SHILLINGFORD, FRCP, professor
}

single chest lead (V5) when compared with the findings at coronary arteriography were $95 \%, 68 \%$, and $64 \%$ respectively, while the specificities of the three lead systems did not differ significantly.

The technique of precordial surface mapping after exercise may easily be applied in clinical practice and requires only conventional equipment available in most hospitals. It effectively aids diagnosis of coronary artery disease.

\section{Introduction}

Exercise electrocardiography is a well-established non-invasive aid in diagnosing coronary artery disease. ${ }^{12}$ Initially only a single chest lead was used, but in an attempt to improve the specificity and sensitivity new lead systems have been tried. Recent studies have used the 12-lead electrocardiogram (ECG) and the Frank system of three orthogonal leads. ${ }^{34} \mathrm{~A}$ technique has been described for recording the precordial surface map before and after exercise using conventional equipment available in most hospitals. ${ }^{5}$ The purpose of this study was to show the superiority of this technique over the orthogonal and single chest-lead systems in diagnosing coronary artery disease. 


\section{Patients and methods}

One hundred and nine consecutive patients (93 men, 16 women) were studied before undergoing diagnostic coronary arteriography. The mean age was 48 years. In all patients a 16-point precordial ECG was recorded with a direct-writing ink-jet Mingograf (Elema Schonander) recording on four channels simultaneously. The 16 electrodes were connected to the ECG machine by a four-way switching system. The 16 unipolar electrodes were evenly distributed over the left hemithorax and connected to a central Wilson terminal. The C3 position (see figure) corresponded exactly to V5 and was selected to be the single chest lead. Graded maximal exercise tests

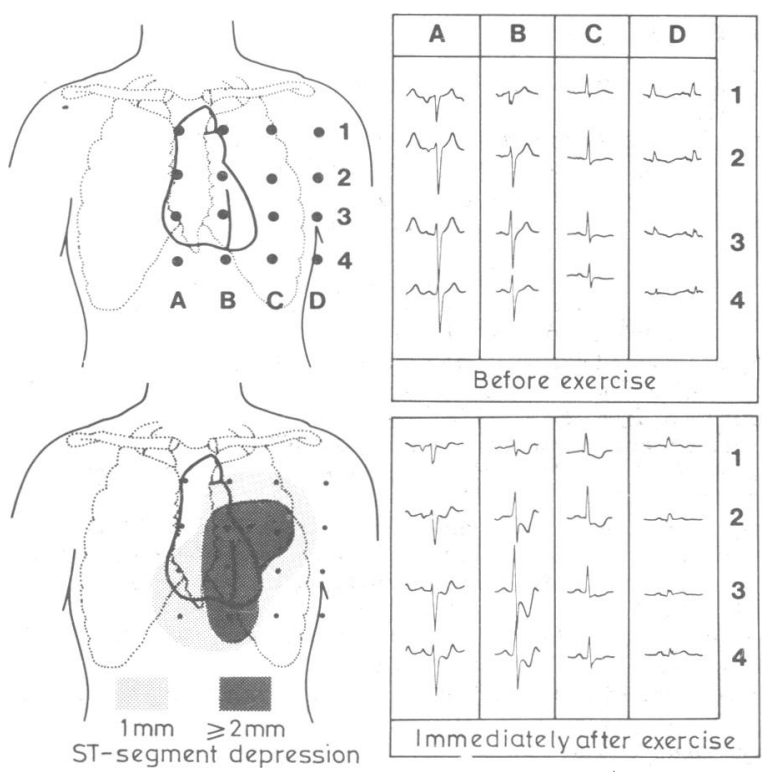

Example of the 16 ECG complexes recorded before and immediately after exercise in patient with severe narrowing of left anterior descending coronary artery. ST-segment depression was present immediately after exercise (contour map of precordial area shown in left hand panel).

were performed using a bicycle ergometer. ${ }^{3}$ Recordings were made before exercise, immediately after, and then at regular intervals for 10 minutes or until the ECG had returned to the pre-exercise resting state. Connecting each patient took 10-15 minutes, and each 16-lead precordial map took about 10 seconds to record. In addition, 53 of these patients underwent a graded maximal exercise test on a treadmill. ${ }^{6}$ All these patients had orthogonal three-lead ECGs recorded before and at regular intervals after exercise with a Hewlit Packard 1513B three-channel ECG. All results of the exercise tests were reported before the patients underwent coronary arteriography.

We used the criteria of the Scandinavian Committee on ECG Classification to interpret the results of the exercise tests. ${ }^{7}$ STsegment changes were recorded from the $P Q$ segment and were considered to be depressed when there was $1 \mathrm{~mm}$ or more of shift lasting for $0.08 \mathrm{~s}$ or longer. ST-segment elevation was measured $0.06 \mathrm{~s}$ from the end of the QRS complex and was considered significant when greater or equal to $1 \mathrm{~mm}$. Contour maps of the area of STsegment change were drawn for each precordial surface map. ${ }^{8}$

All patients underwent left ventricular angiography, and coronary arteriography was performed by the Judkins technique. ${ }^{9}$ The radiologists and cardiologists who carried out the investigation interpreted the coronary arteriograms without knowledge of the results of the exercise tests.

Statistical analysis was performed using a $\chi^{2}$ test and paired $t$ tests.

\section{Results}

The figure shows an example of the 16 ECG complexes recorded before and immediately after exercise in a patient with significant narrowing of the left anterior descending coronary artery. Also shown is the contour map of the area of ST-segment depression projected on to the front of the chest. In all patients ECG tracings were of sufficient quality for the ST-segment changes to be interpreted.
Eighty-five of the 109 patients had significant $(\geqslant 70 \%)$ narrowing of at least one major coronary artery - the right artery alone in five, the left alone in 33 , and mixed coronary disease in 47 . In 81 of these 85 patients $(95 \%)$ significant ST-segment changes were recorded with the exercise precordial mapping (table I). In contrast, in only $54(64 \%)$ were changes recorded with a single chest lead (V5; P $<0.01)$. Two of the 24 patients with normal coronary arteries or only minor irregularities had ST-segment changes on the precordial surface map after exercise; both were women, one having a prolapsing posterior mitral valve leaflet and the other developing ventricular tachycardia on exercise.

Table II compares the results obtained with the precordial exercise mapping and those obtained from the exercise test with three orthogonal leads. Similar maximum heart rates were achieved with the two tests $(P \quad 0 \cdot 05)$. In the 53 patients who underwent an orthogonallead stress test on the treadmill in addition to surface mapping after exercise a maximum heart rate of 123-167 (mean 152) beats/min was achieved on the bicycle ergometer and 130-167 (mean 152) beats/min on the treadmill. Forty of the 53 patients had coronary artery disease by the criteria described above. Significant ST-segment changes were recorded in 38 of these 40 patients $(95 \%)$ by precordial surface mapping and in $27(68 \%)$ by the orthogonal-lead system $(\mathrm{P}<0.01)$. Eleven patients had ST-segment changes on the precordial map but none detected with the orthogonal leads.

Table III shows the sensitivities and specificities of the three techniques. Precordial surface mapping showed a significant improvement in diagnostic accuracy when compared with the other two techniques $(\mathbf{P}<0 \cdot 01)$.

TABLE I-Results of precordial surface mapping and single chest lead compared with those of coronary arteriography in 109 patients

\begin{tabular}{|c|c|c|c|c|c|c|}
\hline \multirow{2}{*}{\multicolumn{2}{|c|}{$\begin{array}{c}\text { Coronary } \\
\text { arteriography }\end{array}$}} & \multicolumn{2}{|c|}{ Precordial mapping } & \multicolumn{2}{|c|}{ Single chest lead } & \multirow{2}{*}{ Total } \\
\hline & & Positive & Negative & Positive & Negative & \\
\hline $\begin{array}{ll}\text { Positive } & \ldots \\
\text { Negative } & \ldots\end{array}$ & $\ldots$ & $\begin{array}{r}81 \\
2\end{array}$ & $\begin{array}{r}4 \\
22\end{array}$ & $\begin{array}{r}54 \\
2\end{array}$ & $\begin{array}{l}31 \\
22\end{array}$ & $\begin{array}{l}85 \\
24\end{array}$ \\
\hline Total & & 83 & 26 & 56 & 53 & 109 \\
\hline
\end{tabular}

TABLE II-Results of precordial surface mapping and orthogonal system compared with those of coronary arteriography in 53 patients

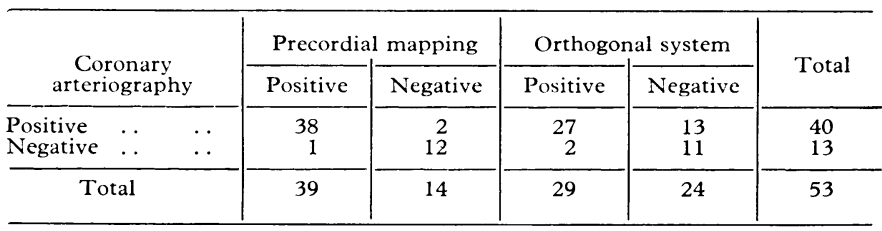

TABLE III-Sensitivity and specificity of exercise testing with precordial surface mapping, orthogonal leads, and single chest lead

\begin{tabular}{c|c|c|c}
\hline & Precordial mapping & Orthogonal leads & Single chest lead \\
\hline Specificity (") & 92 & 85 & 92 \\
Sensitivity (") & 95 & 68 & 64 \\
\hline
\end{tabular}

\section{Discussion}

The development of non-invasive techniques that accurately diagnose coronary artery disease is essential if unnecessary invasive investigations are to be avoided. Although much information may be obtained from studying circulatory function at rest, that obtained after stress is more sensitive and informative. ${ }^{10}$ Widespread interest in the changes in the ECG after exercise followed the development of the "two-step stress test" introduced by Master and Jaffe. ${ }^{11}$ The results of exercise testing obtained with a single chest lead have been compared with the findings at coronary arteriography. ${ }^{12} 13$ In most of the studies a sensitivity of $48-66 \%$ and specificity of $80-83 \%$ have been found. In an attempt to improve these results progressive multistage tests on a treadmill or bicycle ergometer have been 
introduced with reported sensitivities varying between $60 \%$ and $80 \%{ }^{14}{ }^{15}$ More recently modifications have led to the use of multiple- and orthogonal-lead systems, ${ }^{34}$ with a reported sensitivity of $80 \% .^{3}$ Vector cardiographic analysis has been applied to the exercise test with the Frank system of three orthogonal leads ${ }^{16}$; this gives a sensitivity of $85^{\circ} \%$. These results are comparable with the findings of Simoons and Hugenholtz, who used computer averaging techniques and multivariate analysis of ST-segment data. ${ }^{17}$ Although vector cardiographic and computer analyses achieve good results, they require special expertise and equipment that is not usually available in most centres. Precordial surface mapping, on the other hand, may be performed with standard equipment, and no special training is needed to interpret the records.

In this study the orthogonal system and precordial surface mapping were compared using a treadmill and bicycle ergometer respectively. This introduced an extra variable, whose effect we tried to minimise as far as possible by using the same end-points for the period of exercise in each patient-that is, fatigue, dyspnoea, or chest pain. The similar maximum heart rates achieved in both tests to some extent provided objective evidence that the heart had been subjected to similar stresses on both occasions.

This investigation showed the sensitivity of surface mapping to be significantly superior to that of either the orthogonal system or a single chest lead. Clearly, by recording from 16 precordial positions areas of ischaemia that are inaccessible to the standard exercise ECG may be detected. In addition, the precordial surface map recorded after exercise adds an extra dimension to exercise electrocardiography by obtaining a measure of the area of ST-segment changes that are projected on to the front of the chest. Serial semi-quantitative observations may be made in each patient when evaluating medical and surgical treatment.
In this study we assessed a technique for recording the precordial exercise ECG that had a sensitivity of $95 \%$ when compared with the findings at coronary arteriography. The technique is therefore of value in patients presenting with chest pain and should reduce the need for angiography.

This work was supported in part by a grant from the British Heart Foundation. We are grateful to Professor J F Goodwin, Dr C M $\Rightarrow$ Oakley, and Dr D M Krikler for allowing us to study patients under $\stackrel{\mathscr{S}}{\stackrel{9}{2}}$ their care.

\section{References}

${ }^{1}$ Rosing, D R, Reicheck, N, and Perloff, J K, American Heart fournal, 1974, 87, 584 .

2 Sheffield, L T, Cardiovascular Clinics, 1975, 6, 93.

${ }^{3}$ Mason, R E, et al, Circulation, 1967, 36, 517.

${ }^{4}$ Frank, E, Circulation, 1956, 13, 737.

${ }^{5}$ Fox, K M, Selwyn, A P, and Shillingford, J P, British Heart fournal. OO In press.

${ }^{6}$ Bruce, R A, Annals of Clinical Research, 1971, 3, 323.

7 Scandinavian Committee on ECG Classification, Acta Medica Scandinavica, 1967, suppl No 481, p 1.

8 Reid, D S, Pellides, L J, and Shillingford, J P, British Heart fournal, ! $1971,33,370$.

9 Judkins, M P, Radiology, 1967, 89, 815.

10 Epstein, S E, et al, Circulation, 1967, 35, 1049

${ }^{11}$ Master, A M, and Jaffa, H L, fournal of the Mount Sinai Hospital, 1941, 7,629 .

${ }^{12}$ Fitzgibbon, G M, et al, Annals of Internal Medicine, 1971, 74, 509.

${ }^{13}$ Phibbs, B P, and Bucknells, L J, American Heart fournal, 1975, 90, 275.

${ }^{14}$ Roitman, D, Jones, W B, and Sheffield, L T, Annals of Internal Medicine, 1970, 72, 641.

${ }^{15}$ Martin, C M, and McConahay, D R, Circulation, 1972, 46, 956.

${ }_{16}$ Kilpatrick, D, Lancet, 1976, 2, 332.

17 Simoons, M L, and Hugenholtz, P G, Circulation, 1977, 56, 552.

\title{
Effects of propranolol and metoprolol on the peripheral circulation
}

\author{
P D MCSORLEY, D J WARREN
}

than metoprolol. Similar changes were seen in the hypertensive patients.

Propranolol should be used with care in patients with

\section{Summary and conclusions}

The effects of single doses of propranolol and metoprolol on skin temperature and skin and muscle blood flow were compared in $\mathbf{1 0}$ normal subjects and four patients with essential hypertension. In normal subjects the mean skin temperature fell by $1.300 .62 \mathrm{C} 90$ minutes after $80 \mathrm{mg}$ propranolol and $0 \cdot 15+0.05 \mathrm{C}$ after $100 \mathrm{mg}$ metoprolol. Skin blood flow and resting muscle blood flow were not affected by metoprolol but fell significantly after propranolol. Both drugs reduced post-exercise muscle hyperaemia, propranolol by more

\footnotetext{
Hypertension Laboratory, Department of Renal Medicine, University of Southampton, St Mary's Hospital, Portsmouth PO3 6AD

$P$ D MCSORLEY, MB, MRCP, lecturer in clinical pharmacology

D J WARREN, DPHIL, MRCP, consultant physician and senior lecturer in nephrology
}

known vascular disease.

\section{Introduction}

The importance of the cardioselectivity of beta-adrenergic neurone blocking drugs (beta-blockers) in relation to airways obstruction is well documented. ${ }^{1}$ It is less clear whether $\stackrel{0}{=}$ selectivity is an advantage in relation to other side effects of $\stackrel{\Phi}{\rightarrow}$ beta-blockers. Cold hands in patients taking propranolol were 0 noted early" but not always reported in other studies. ${ }^{3}$ It has 0 been suggested' that Raynaud's phenomenon occurs in $59 \%$ of patients taking propranolol and $35^{\circ}$ " of patients taking atenolol, $\mathbb{\mathbb { D }}$ though the conduct of that study was questioned." Cold hands are more common during treatment with a cardioselective betablocker than placebo, ${ }^{6}$ but of greater clinical concern is the 8 report of peripheral gangrene in a patient receiving propranolol and in another taking the relatively cardioselective drug $\frac{0}{7}$ metoprolol.

We have measured skin temperature and skin and muscle blood flow after doses of propranolol and metoprolol to see 